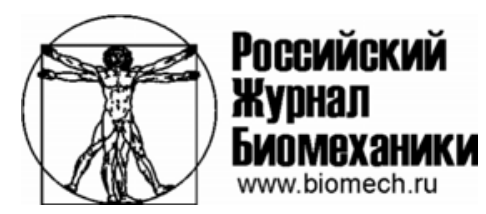

\title{
ПРИМЕНЕНИЕ ФАЗОВОГО ПРОСТРАНСТВА ДЛЯ АНАЛИЗА МЫШЕЧНОЙ АКТИВНОСТИ ПРИ БЕГЕ
}

\author{
Л.Л. Ципин \\ Национальный государственный университет фризической культуры, спорта и здоровья имени \\ П.Ф. Лесгафта, Россия, 190121, Санкт-Петербург, ул. Декабристов, 35, e-mail: \\ spb_biomechanics@rambler.ru
}

\begin{abstract}
Аннотация. Метод фразового пространства является методом исследования различных, в том числе биологических, систем. Целью работы является анализ мышечной активности квалифицированных бегунов на средние дистанции посредством построения фразовых траекторий следующих мышц: $m$. rectus femoris, $m$. biceps femoris, $m$. gastrocnemius в координатах «относительная длина - скорость сокращения мышцы», а также регистрации электрической активности мышц и кинематических характеристик движений при беге со скоростью 6,7 м/с. Обнаружено, что на протяжении цикла движения $m$. rectus femoris активна в течение двух периодов, первый из которых наступает перед началом фразы опоры, а второй соответствует фразе переноса. В обоих периодах мышца работает в эксцентрическом режиме. Средняя амплитуда электромиограммы, косвенно характеризующая развиваемое мышцей усилие, в первом периоде выше, чем во втором. M. biceps femoris также активна в течение двух периодов, первый из которых соответствует окончанию фразы переноса ноги, а второй начинается с постановки ноги на опору. Бо́льшую часть первого периода мышца работает в эксцентрическом режиме, а во втором - в концентрическом. Средняя амплитуда электромиограммы в первом периоде значительно выше, чем во втором, что свидетельствует о его значении в структуре движения. M. gastrocnemius активна на протяжении одного периода, который начинается при опускании ноги перед ее постановкой на опору. Примерно половину периода мышца работает в эксцентрическом режиме, вторую половину - в концентрическом, что создает благоприятные условия для рекуперации энергии упругой деформации. Поскольку кроме условий и режимов работы мышц фазовые траектории позволяют оценить активность двигательного анализатора, это открывает возможность для сравнения величины и структуры сенсорного притока от работающих мышц при выполнении соревновательного и специальных упражнений и тем самым создает предпосылки для их оптимального выбора.
\end{abstract}

Ключевые слова: бег на средние дистанции, фазовое пространство, фразовые траектории мышц, электрическая активность мышц, двигательный анализатор.

\section{ВВЕДЕНИЕ}

Метод фазового пространства является одним из распространенных методов исследования нелинейных систем [2]. Исторически понятие фазового пространства было введено для более удобного и наглядного изучения поведения механических объектов и систем. Точки фазового пространства, образующие при движении фазовые траектории, однозначно характеризуют все возможные состояния данной системы. 
Для механических систем координатами фазового пространства служат пространственные координаты и их импульсы. В случае двумерного фазового пространства фазовые траектории представляют собой кривые на фазовой плоскости.

При изучении биологических систем метод фазового пространства использовался рядом исследователей. В.В. Александров с соавторами применяли фазовые траектории для выявления вида взаимосвязи между различными признаками электрокардиограммы человека [1]. И.Б. Клочков на основе сравнительной оценки фазовых траекторий исследовал качество протезов бедра и голени человека [6]. Совместно с соавторами им сконструирована система анализа обобщенных фазовых портретов движения на тренажерах с биологической обратной связью [7]. В.А. Богданов применил фазовые траектории для изучения движений в суставных сочленениях ноги при ходьбе [3, 4]. K. Jaworek, A. Ferenc использовали фазовые диаграммы в координатах «межзвенный угол - угловая скорость» для анализа результатов ходьбы и бега. Ими показано, что этот способ представления данных может найти широкое применение в системах коррекции движений [16, 17]. А.Г. Фельдман предложил использовать фазовые траектории в координатах «текущая длина - скорость изменения длины мышцы» для изучения механизмов координации движений $[12,13]$. Он проанализировал механизмы управления активностью мотонейронного пула при решении простейших двигательных задачах. Наиболее полно метод фазового пространства при изучении целостных двигательных действий представлен в работах А.В. Самсоновой с соавт. [9-11, 18, 19]. Ею впервые получены фазовые траектории мышц нижних конечностей человека при спринтерском и барьерном беге, а также педалировании в различном темпе.

Характерной особенностью фазовых траекторий мышц в координатах «длина скорость сокращения мышцы» является то, что они дают представление об активности двигательного анализатора. Это связано с тем, что интенсивность сенсорного притока от афферентов работающей мышцы (мышечных веретен) обусловлена длиной мышцы и скоростью ее изменения. В свою очередь, сенсорная информация служит важной и неотъемлемой частью системы управления движениями. Учитывая то, что основной задачей спортивной тренировки является повышение работоспособности, а физиологическая основа ее заключается в ответной реакции на афферентную импульсацию, целесообразно при анализе фазовых траекторий состояний мышц учитывать еще один фактор, характеризующий интенсивность ответной реакции, величину электрической активности мышц. В определенном диапазоне средняя амплитуда электромиограммы работающей мышцы пропорциональна развиваемому ею усилию [15]. Оценив это усилие в цикле движения или в процессе выполнения всего упражнения, можно определить направленность упражнения и степень его тренирующего воздействия при развитии силовых качеств отдельных мышц.

Цель настоящего исследования заключалась в анализе мышечной активности квалифицированных бегунов на средние дистанции на основе применения комплексного метода построения фазовых траекторий мышц, определения величины их электрической активности и регистрации кинематических характеристик движений. Проведенное ранее подобное исследование основывалось на использовании стандартной киносъемки, записи электромиограммы посредством шлейфового осциллографа и ручной обработки данных, что не позволяло провести в полном объеме и с необходимой степенью точности анализ фазовых траекторий мышц [14]. 


\section{МАТЕРИАЛЫ И МЕТОДЫ ИССЛЕДОВАНИЯ}

В исследовании участвовали три спортсмена, мастера спорта, специализирующиеся в беге на средние дистанции. Выполнялся бег на дистанции 800 м со средней скоростью $6,7 \mathrm{~m} / \mathrm{c}$. Для того чтобы учесть влияние утомления, замеры биомеханических и электрофизиологических параметров производились в конце дистанции. Осуществлялась синхронная видеосъемка и регистрация электромиограмм мышц нижних конечностей бегунов. Видеосъемка проводилась камерой Casio Exilim Pro EX-F1 (Япония), установленной на специальном штативе. Расстояние от камеры до спортсмена -4 м, частота съемки - 60-300 кадр/с. Камера располагалась на высоте 0,5 м, оптическая ось объектива была перпендикулярна сагиттальной плоскости тела спортсмена. В непосредственной близости за спортсменом находился калибровочный экран. Проекции осей суставов на теле отмечались контрастными маркерами диаметром 0,003 м. Регистрация электрической активности мышц выполнялась восьмиканальным аппаратно-программным комплексом «Миотон» (ОКБ «РИТМ», г. Таганрог, Россия). Аппаратный блок комплекса соединялся с ноутбуком USB-кабелем, длина которого была увеличена за счет удлинителя с усилителем, что позволяло производить запись электромиограмм на заданном отрезке дистанции. Применялись кнопочные биполярные отводящие электроды $R E F$ F3010 размером 41×21 мм (Италия). Электроды устанавливались в местах локализации двигательных точек мышц вдоль мышечных волокон. Обработка огибающих электромиограммы осуществлялась посредством программного обеспечения StabMed2. Средняя амплитуда электромиограммы определялась как отношение суммарной электрической активности к длительности активности на выделенном участке электромиограммы. Регистрировалась электрическая активность следующих мышц нижней конечности: $m$. rectus femoris, $m$. biceps femoris, m. gastrocnemius.

Расчет морфометрических характеристик мышц, необходимых для построения фазовых траекторий (длины и скорости сокращения мышцы), проводился с помощью программы MORFOMETR (разработчик - инженер кафедры биомеханики СПбГУФК им. П.Ф. Лесгафта, Санкт-Петербург, В.Ю. Гнедовский). В основу расчета положены модели мышц A. Pedotti [20] и зависимости, связывающие длину мышц нижних конечностей с межзвенными углами [8]. Программа предполагает введение координат опорных точек (проекций осей суставов) с экрана монитора при использовании масштабирования и констант, характеризующих места прикрепления мышц. Результаты расчета импортируются в Microsoft Excel. Для сопоставления значений длины и скорости сокращения мышц у разных испытуемых рассчитывалась не абсолютная, а относительная длина мышц. Она определялась как процентное отношение разности длины мышцы и ее эквитонической длины к длине звена. Эквитоническая длина мышцы соответствует положению звеньев тела, при котором значение угла между тазом и бедром составляет $120^{\circ}$, между бедром и голенью $-130^{\circ}$, между голенью и стопой $-90^{\circ}[5]$.

\section{РЕЗУЛЬТАТЫ И ИХ ОБСУЖДЕНИЕ}

На рис. 1-3 показаны фазовые траектории мышц одного из испытуемых. На них схематично показано положение нижних конечностей в моменты начала и окончания периодов активности мышц, в течение которых амплитуда электромиограммы отлична от нуля. 
Для $m$. rectus femoris наблюдаются два периода активности (рис. 1). Первый из них (I) наступает перед началом фазы опоры и заканчивается до ее окончания. Мышца в этом периоде работает в эксцентрическом режиме, и ее функция заключается в противодействии сгибанию ноги в коленном суставе при амортизации. Максимум активности приходится на начало опоры. Перед постановкой ноги на опору в момент начала активности мышцы угол в коленном суставе максимален $\left(153^{\circ}\right)$, а в момент окончания активности - минимален $\left(133^{\circ}\right)$. Вторая нога (на рисунке показана тонкой линией) в этот момент совершает перенос.

Второй период активности (II) соответствует фазе переноса. Мышца в этом периоде также работает в эксцентрическом режиме, и ее функция заключается в смене направления движения бедра и сгибании в тазобедренном суставе при одновременном инерционном сгибании голени и уменьшении угла в коленном суставе. Максимум активности приходится на момент смены направления движения бедра.

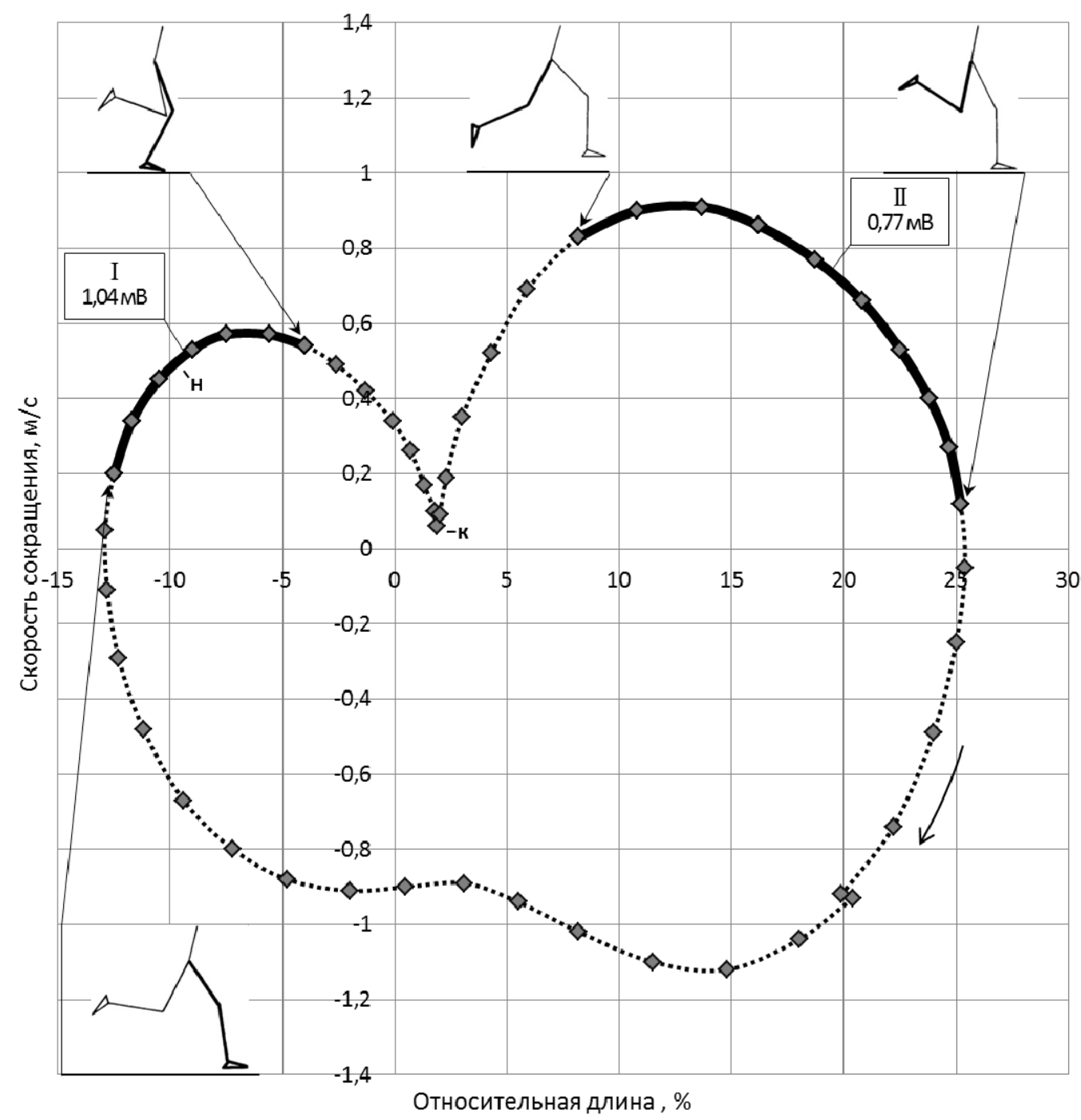

Рис. 1. Фазовая траектория $m$. rectus femoris при беге со скоростью $6,7 \mathrm{~m} / \mathrm{c}$. Жирные линии - мышца активна. I и II - периоды активности. Цифры на сносках - средняя амплитуда электромиограммы; н - начало опоры; к - конец опоры 
Вторая нога в это время заканчивает перенос. Отличие периодов I и II состоит в том, что в первом из них меньше изменяется как длина, так и скорость сокращения мышцы. В первом случае изменение относительной длины мышцы происходит в области отрицательных значений, а во втором - в области положительных значений. Можно предположить, что это связано с различным вкладом в сокращение последовательных и параллельных упругих компонентов мышцы. Средняя амплитуда электромиограммы в первом периоде выше, чем во втором, что свидетельствует о большей значимости активности мышцы в период, соответствующий фазе опоры при беге с данной скоростью.

Для $m$. biceps femoris также наблюдаются два периода активности (рис. 2). Первый из них соответствует окончанию фазы переноса ноги. Бо́льшую часть периода мышца работает в эксцентрическом режиме, и только в конце переходит в концентрический режим.

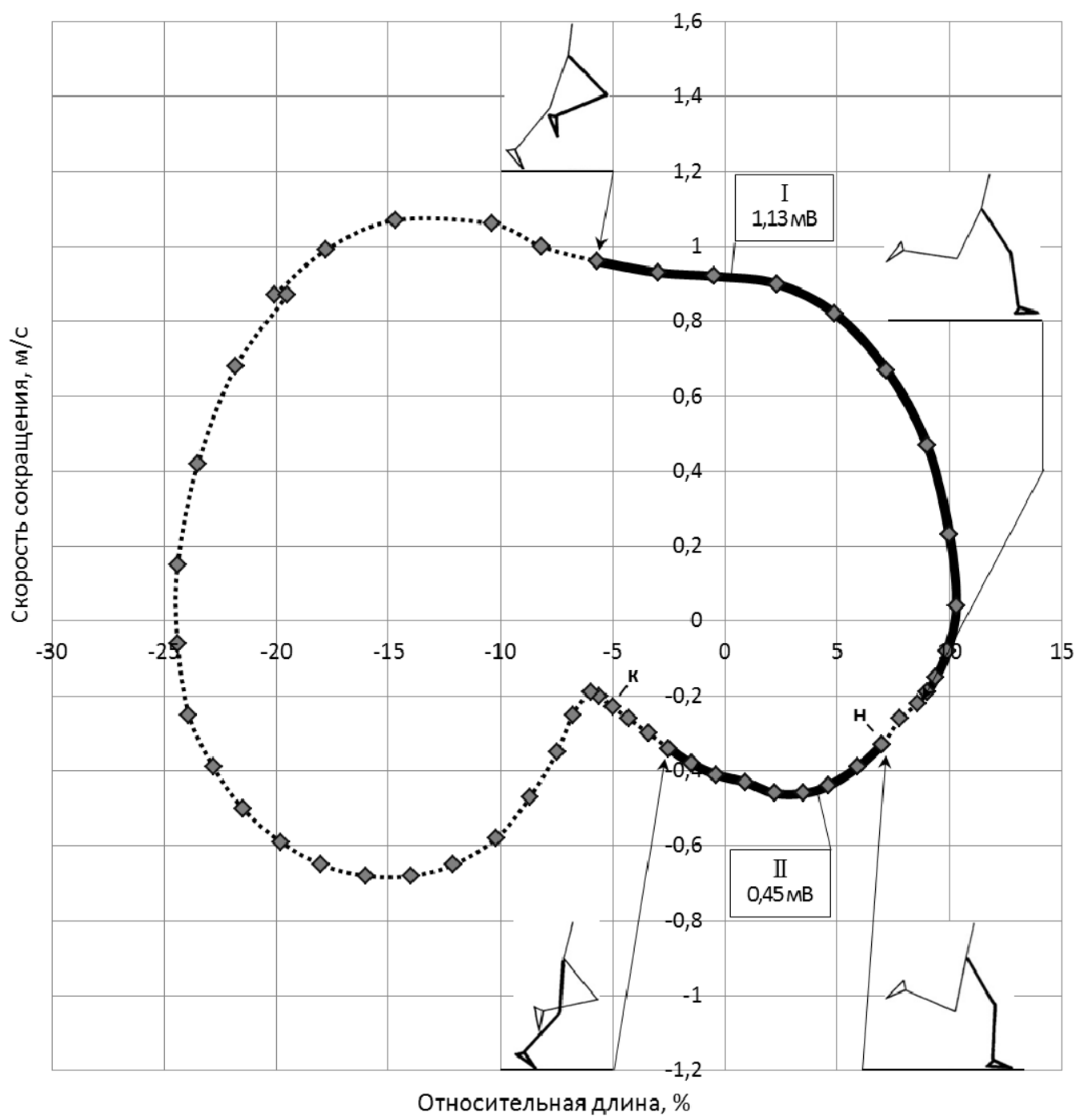

Рис. 2. Фазовая траектория $m$. biceps femoris при беге со скоростью $6,7 \mathrm{~m} / \mathrm{c}$. Жирные линии - мышца активна. I и II - периоды активности. Цифры на сносках - средняя амплитуда электромиограммы; н - начало опоры; к - конец опоры 
Функция мышцы в первом периоде активности заключается в смене направления движения бедра и разгибании в тазобедренном суставе при одновременном инерционном разгибании голени перед постановкой ноги на опору. Максимум активности приходится на момент смены направления движения бедра. В момент окончания активности мышцы угол в коленном суставе максимален и составляет $153^{\circ}$. Существенно, что окончание активности $m$. biceps femoris в период I совпадает с началом активности $m$. rectus femoris в период I. Вторая нога в это время заканчивает отталкивание и начинает перенос. Второй период активности начинается с постановки ноги на опору и заканчивается перед окончанием фазы опоры. Мышца в этот период работает в концентрическом режиме. Ее функция заключается в разгибании в тазобедренном суставе, что при незначительном уменьшении угла в коленном суставе, которому препятствует $m$. rectus femoris, создает условия для горизонтального продвижения общего центра масс на опоре. Максимум активности приходится на момент наибольшего сгибания ноги в коленном суставе. Вторая нога в это время совершает перенос. Периоды I и II различаются как по диапазону изменения длины и скорости сокращения мышцы, так и по режиму еe работы.

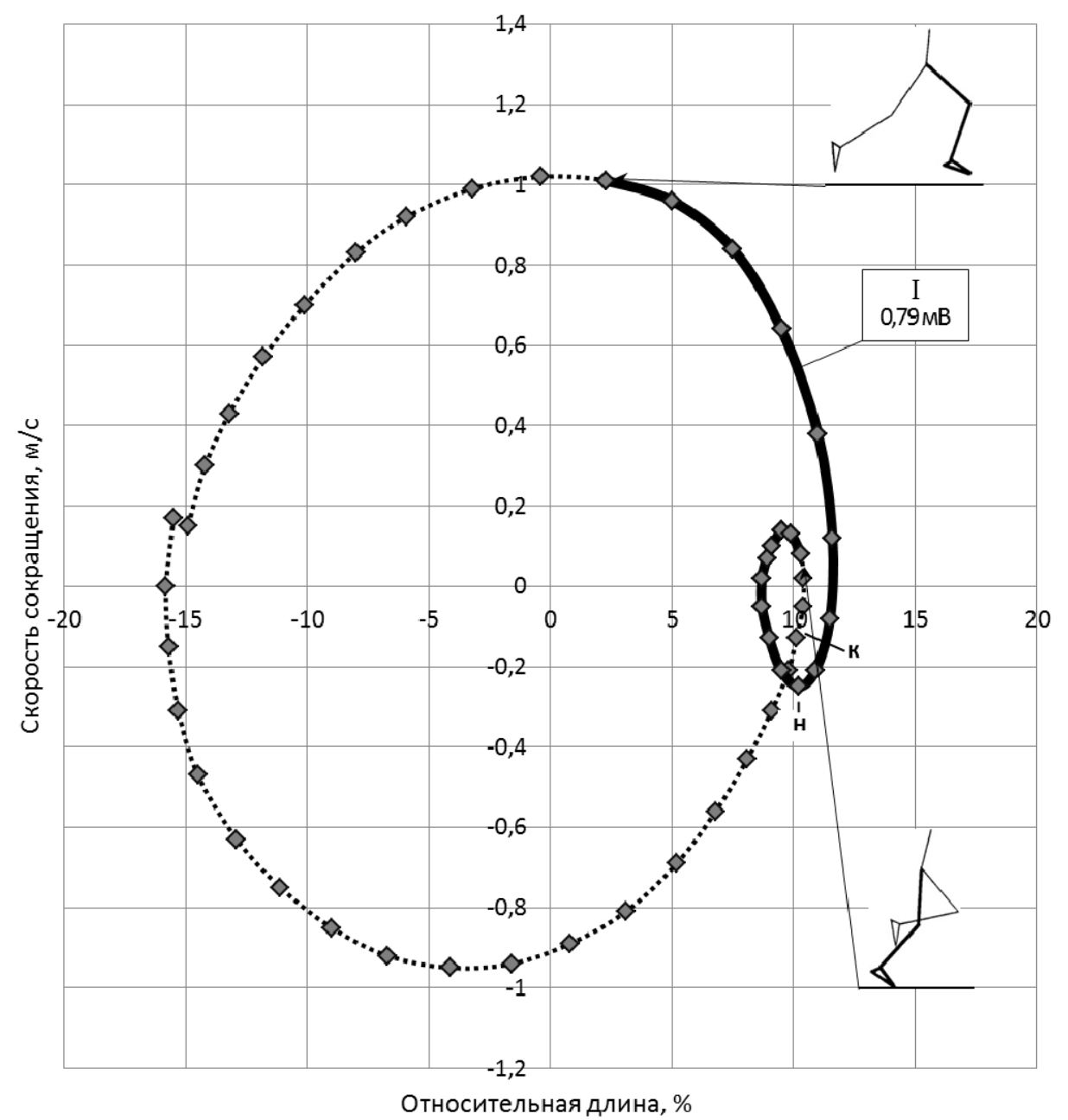

Рис. 3. Фазовая траектория $m$. gastrocnemius при беге со скоростью 6,7 м/с. Жирная линия - мышца активна. I - период активности. Цифры на сноске средняя амплитуда электромиограммы; н-начало опоры; к-конец опоры 
В первом случае при переходе от эксцентрического к концентрическому режиму работы создается возможность рекуперации энергии упругой деформации.

Изменение относительной длины $m$. biceps femoris в обоих периодах активности происходит преимущественно в области положительных значений. Средняя амплитуда электромиограммы в первом периоде значительно выше, чем во втором, что указывает на бо́льшую значимость активности мышцы в конце фазы переноса ноги при беге с данной скоростью.

M. gastrocnemius активна на протяжении одного периода, который начинается при опускании ноги перед ее постановкой на опору, и заканчивается перед завершением фазы опоры (рис. 3). Окончание активности m. gastrocnemius совпадает с окончанием второго периода активности $m$. biceps femoris. Примерно половину периода мышца работает в эксцентрическом режиме, вторую половину в концентрическом. Это в большей степени, чем у других мышц, создает условия для рекуперации энергии упругой деформации при отталкивании и выражается в наличии петли на фазовой траектории. Функция мышцы заключается в предварительном сгибании стопы при одновременном инерционном разгибании голени перед постановкой ноги на опору. Она участвует в противодействии амортизационному разгибанию стопы и в ее сгибании при отталкивании. Максимум активности приходится на начало опоры, что соответствует наибольшему сгибанию стопы в голеностопном суставе, угол в котором составляет $114^{\circ}$. Вторая нога в это время совершает перенос. Изменение относительной длины $m$. gastrocnemius на протяжении всего периода ее активности происходит в области положительных значений.

Фазовые траектории мышц при беге у двух других испытуемых имеют те же характерные особенности. Исключение составляет отсутствие промежутка между периодами активности I и II $m$. biceps femoris у одного из спортсменов. Однако на электромиограмме на месте промежутка наблюдается значительное снижение электрической активности.

\section{ЗАКЛЮЧЕНИЕ}

Из анализа фазовых траекторий мышц при беге на средние дистанции следует, что активность каждой мышцы и связанная с ней организация движений характеризуется в разные периоды определенным значением морфометрических и электрофизиологических показателей. Для $m$. rectus femoris большое значение имеет период активности, соответствующий фазе опоры, для m. biceps femoris - период, предшествующий фазе опоры, для $m$. gastrocnemius - период активности в целом. В эти периоды наблюдается одновременная активность в различных режимах рассмотренных мышц - синергистов и антагонистов, что приводит к созданию необходимой жесткости и эффективной передаче усилий между группами мышц и звеньями нижней конечности. Поскольку кроме режимов работы мышц фазовые траектории позволяют оценить активность двигательного анализатора, это открывает перспективы для сравнения величины и структуры сенсорного притока от работающих мышц при выполнении соревновательного и специальных упражнений. Такое сравнение делает возможным подбор эффективных упражнений, наиболее соответствующих технике соревновательного упражнения и оказывающих на спортсмена высокое тренирующее воздействие. 


\section{СПИСОК ЛИТЕРАТУРЫ}

1. Александров В.В., Шеповальников А.Н., Шнейдеров В.С. Графика физиологических данных. Л.: Наука, 1981. - 111 с.

2. Бесекерский В.А., Попов Е.П. Теория систем автоматического регулирования. - М.: Наука, 1975. $768 \mathrm{c.}$

3. Богданов В.А. Особенности регулирования локомоторных движений человека // Биофизика. - 1985. Т. 30, № 5. - С. 900-904.

4. Богданов В.А. Об энергетической инвариантности некоторых привычных движений // Биофизика. 1988. - Т. 33, № 1. - С. 135-139.

5. Гурфинкель В.С., Шик М.Л., Коц Я.М. Регуляция позы человека. - М.: Наука, 1965. - 256 с.

6. Клочков И.Б. Аналитический и аппаратурный методы исследования и оценка биодинамики ходьбы в норме и на протезах: дис. ... канд. техн. наук. - Л., 1973. - 156 с.

7. Клочков И.Б., Поветкин Ю.С., Жуков В.А., Соломонов Ю.Ф. Применение ЭВМ для анализа обобщенных фазовых портретов движения в тренажерах с биологической обратной связью // Биомеханика спорта: тезисы докл. VI Всесоюз. конф. - Чернигов, 1989. - С. 88-89.

8. Козлов И.М., Самсонова А.В., Соколов В.Г. Морфометрическая характеристика мышц нижних конечностей при движениях человека // Архив анатомии, гистологии и эмбриологии. - 1988. - Т. 94, № 2. - C. 47-52.

9. Самсонова А.В., Кичайкина Н.Б., Козлов И.М. Фазовые портреты мышц // Теория и практика физической культуры. - 1993. - № 1. - С. 1-3.

10. Самсонова А.В. Моторные и сенсорные компоненты биомеханической структуры физических упражнений: дис. ... д-ра пед. наук. - СПб., 1997. - 310 с.

11. Самсонова А.В. Моторная и сенсорная функции мышц в биомеханике локомоци. - СПб.: СПбГУФК им. П.Ф. Лесгафта, 2007. - 152 с.

12. Фельдман А.Г. Механические свойства скелетной мышцы и их регуляция нервной системой // Физиология движений. - Л.: Наука, 1976. - С. 38-68.

13. Фельдман А.Г. Центральные и рефлекторные механизмы управления движениями. - М.: Наука, 1979. $-184 \mathrm{c}$.

14. Ципин Л.Л. Специальные упражнения сопряженного воздействия как средство тренировки бегунов на средние дистанции в подготовительном периоде: дис. ... канд. пед. наук. - СПб., 1991. - 218 с.

15. Ципин Л.Л., Захаров Ф.Е. Оценка динамической силы мышц спортсменов по показателям их электрической активности // Культура физическая и здоровье. - 2013. - № 1 (43). - С. 51-54.

16. Jaworek K. Application of phase diagrams to the analysis of human motion studies // Biology of Sport. 1988. - Vol. 5, suppl. 1. - P. 47-54.

17. Jaworec K., Ferenc A. The method of assessing the biomechanical parameters of human gait // Lecture notes of the ICB seminars biomechanics. - Warsaw, 1995. - P. 307-330.

18. Kozlov I.M., Samsonova A.V. Muscles activity control when running // 6-th International Symposium on Biomechanics in Sport. - Bozeman, Montana: Montana State University, 1988. - P. 22.

19. Kozlov I.M., Kichaikina N.B., Samsonova A.V. The phases of muscular activity as the method of study of the movements control // Proceedings of the 8-th International Symposium «Biomechanics in Sports». Prague, 1990. - P. 14-15.

20. Pedotti A. A study of motor coordination and neuromuscular activities in human locomotion // J. Biolog. Cybern. - 1977. - Vol. 26, № 1. - P. 53-62.

\section{APPLICATION OF THE PHASE SPACE FOR ANALYSIS OF MUSCLE ACTIVITY WHILE RUNNING}

\section{L.L. Tsipin (Saint-Petersburg, Russia)}

The method of the phase space is a method of investigation of various systems, including biological ones. The aim of this work is to analyse the muscle activity of qualified middle distance runners through the construction of phase trajectories of the following muscles: $m$. rectus femoris, $m$. biceps femoris, $m$. gastrocnemius in coordinates "the relative length - the speed of muscle contraction", as well as to record the electrical activity of the muscles and kinematic characteristics of motion while running at a speed of $6.7 \mathrm{~m} / \mathrm{s}$. It was 
found that during the cycle of motion, $m$. rectus femoris is active during two periods, the first of which occurs before the beginning of the stance phase and the second one corresponds to the transfer phase. In both periods, the muscle works in the eccentric mode. The average amplitude of electromyogram, indirectly characterizing the effort developed by the muscle, is higher in the first period than in the second one. M. biceps femoris is also active during two periods, the first one of which corresponds to the end of the transfer phase of the foot, and the second one starts with putting the foot on the support. For the most part of the first period, the muscle works in the eccentric mode and during the second period - in the concentric mode. The average electromyogram amplitude in the first period is much higher than in the second one, which shows its importance in the structure of the motion. M. gastrocnemius is active during one period, which begins when lowering the foot before putting it on the support. Approximately half of the period, the muscle works in the eccentric mode and in the other half of the period it works in the concentric mode, which creates favourable conditions for the recovery of the elastic deformation energy. Considering that, in addition to the conditions and modes of operation of the muscles, the phase trajectories allow us to evaluate the activity of the motor analyser, the opportunity is provided to compare the size and structure of the sensory inflow from working muscles when performing competitive and special exercises and which thereby creates the prerequisites for their optimal choice.

Key words: middle-distance running, the phase space, phase trajectories of the muscles, electrical activity of muscles, motor analyser.

Получено 10 сентября 2015 